\title{
A EDUCAÇÃO PRIMÁRIA DE UMA MENINA DA CLASSE TRABALHADORA (NATAL, 1937-1941)
}

\section{MARTA MARIA DE ARAÚJO}

Universidade Federal do Rio Grande do Norte

\section{BERENICE PINTO MARQUES}

Universidade Federal do Rio Grande do Norte

\section{ANA LUIZA MEDEIROS}

Universidade Federal do Rio Grande do Norte

Refletir sobre os elementos educacionais e pedagógicos que influíram na formação escolar da prof.a Margarida de Jesus Cortez, em suas interações intergrupais no Grupo Escolar "João Tibúrcio" da cidade de Natal, de 1937 a 1941, é precisamente o objetivo do presente trabalho. Nesta abordagem de cunho histórico, utiliza-se como fonte documental uma entrevista realizada com a referida professora e a legislação educacional vigente à época de sua educação primária. Esse registro orienta-se, metodologicamente, no processo de análise do corpus, pelo entendimento de Delory-Momberger (2008), para quem a narrativa é o procedimento que se elabora pela reflexão e pela interpretação de uma história de vida e de vida escolar. A constatação conclusiva é a de que a formação escolar, considerada à luz dos elementos educacionais e pedagógicos referentes à educação primária da prof.a Margarida de Jesus Cortez, no Grupo Escolar “João Tibúrcio", revela-se fundamental para a construção da narrativa de uma vida humana, permeada por alcances em nível educacional, cultural e mesmo existencial. De modo mais verticalizado, a formação escolar, em nivel primário, da prof.a Margarida de Jesus Cortez foi essencial para os progressos de sua vida social.

Palavras-chave: Educação primária. Formação escolar. Elementos educacionais e pedagógicos. Interações intergrupais.

\section{ABSTRACT THE ELEMENTARY EDUCATION OF A WORKING-CLASS GIRL (NATAL, 1937-1941)}

Reflecting on the educational and pedagogical elements that influenced the educational formation of Prof. Margarida de Jesus Cortez, in her intergroup interactions in the "João Tibúrcio" School Group of the city of Natal, from 1937 to 1941 , is precisely the objective of 
this work. In this historical intent approach, we used as documental source an interview with the mentioned teacher and the educational legislation in effect at the time of his elementary education. This register is oriented, methodologically, in the process of analysis of the corpus, by the understanding of Delory-Momberger (2008), for whom the narrative is the procedure that is elaborated by the reflection and the interpretation of a history of life and school life. The conclusive finding is that school education, considered in the light of the educational and pedagogical elements related to the elementary education of Prof. Margarida de Jesus Cortez in the "João Tibúrcio" School Group, is crucial for the construction of the narrative of a human life, permeated by educational, cultural and even existential reaches. In a more vertical way, the elementary education of Prof. Margarida de Jesus Cortez was essential for the continuity of her studies and certain social initiations.

Keywords: Elementary education. School formation. Educational and pedagogical elements. Intergroup interactions.

\section{RESUMEN}

\section{LA EDUCACIÓN PRIMARIA DE UNA NIÑA DE LA CLASE TRABAJADORA (NATAL, 1937-1941)}

Reflexionar sobre los elementos educativos y pedagógicos que influyeron en la formación escolar de la profesora Margarita de Jesús Cortez, en sus interacciones intergrupales en el Grupo Escolar "João Tiburcio" de la ciudad de Natal, de 1937 a 1941, es precisamente el objetivo del presente trabajo. En este abordaje de cuño histórico, se utiliza como fuente documental una entrevista realizada con la referida profesora y la legislación educativa vigente a la época de su educación primaria. Este registro se orienta, metodológicamente, en el proceso de análisis del corpus, por el entendimiento de Delory-Momberger (2008), para quien la narrativa es el procedimiento que se elabora por la reflexión y la interpretación de una historia de vida y de vida escolar. La constatación conclusiva es que la formación escolar, considerada a la luz de los elementos educativos y pedagógicos referentes a la educación primaria de la profesora Margarita de Jesús Cortez en el Grupo Escolar "João Tiburcio", se revela fundamental para la construcción de la narrativa de una vida humana, permeada por alcances a nivel educativo, cultural e incluso existencial. De modo más verticalizado, la formación escolar, a nivel primario, de la profesora Margarita de Jesús Cortez fue esencial para la continuidad de sus estudios y de ciertas iniciaciones sociales.

Palabras clave: Educación primaria. Formación escolar. Elementos educativos y pedagógicos. Interacciones intergrupales. 


\section{Introdução}

A prof.a Dr.a Margarida de Jesus Cortez é conhecida (e reconhecida), por haver formulado e dirigido o Centro de Formação de Professores da Secretaria Municipal de Educação de Natal (criado pela Lei Municipal $n^{\circ} 1301$, de 27 de dezembro de 1962), e por ter sido Coordenadora Técnico-Pedagógica da "Campanha de Pé no Chão Também se Aprende a Ler", durante o governo do prefeito Djalma Maranhão (1960-1964).

Entre as atribuições que the competiam como diretora do Centro de Formação de Professores, merecem destaque: a coordenação pedagógica do Curso de Emergência (destinado à preparação de professores para os municípios que mantinham convênios com a Prefeitura de Natal, com duração de três ou quatro meses); a gestão do Colégio Normal (grau colegial, com duração de quatro anos) e do Ginásio Normal (grau ginasial, com duração de três anos).

o Centro de Formação de Professores foi o órgão de coordenação pedagógica da Campanha de Pé no Chão Também se Aprende a Ler, da Escola de Demonstração em nível primário; do Centro de Recursos Audiovisuais e da elaboração da Cartilha de Alfabetização de Adultos. Nas palavras do então Secretário Municipal da Educação, Moacyr de Góes (1980, p. 72; 2009, p. 230), o Centro de Formação de Professores "[...] era o cérebro da Campanha". A professora Margarida de Jesus Cortez foi a figura excepcional "[...] que organizou a Coordenação Pedagógica da Secretaria Municipal de Educação, com grande competência e oferecia subsídios técnicos ao Grupo de Trabalho [da Frente] de Educação Popular do Rio Grande do Norte".

Segundo ainda Moacyr de Góes (2005, p. 16), intelectual comprometido com os problemas humanos e sociais do seu tempo, essa educadora excepcional "[...] é a maior autoridade para falar sobre a teoria e a prática da pedagogia de Pé no Chão". Refletindo sobre o trabalho intelectual e pedagógico que desen- volveu durante a Campanha de Pé no Chão Também se Aprende a Ler, a prof.a Margarida Cortez assim se posiciona:

Hoje, após quarenta anos da minha atuação pedagógica na Campanha, posso analisar e criticar meu trabalho com uma visão atual. 0 uso da pedagogia da Escola Nova foi inteiramente justificado naquele contexto. Era a pedagogia do momento e todos os professores que atuavam naquela época a usavam com relativo sucesso. Como professora de Didática Geral da Faculdade de Filosofia, Ciências e Letras de Natal [...] usava a literatura da época com todos os pressupostos da Escola Nova. (CORTEZ, 2005, p. 178; p. 183-184)

\section{[...]}

Mas o ideário de Paulo Freire, ainda que não tivesse circulado, fazia parte do universo pedagógico de toda a equipe por meio das várias palestras e cursos ministrados por ele, tanto em Natal, quanto em Recife. Entretanto, a metodologia das Unidades de Trabalho foi aprendida pela Coordenação Técnico-Pedagógica da Campanha durante o curso que fez em São Paulo em 1959, com a Doutora Deborah Elkins, da Universidade de Columbia, em Nova York. No cotidiano pedagógico da Campanha, a equipe procurava aliar a nova metodologia com o ideário do educador pernambucano. (CORTEZ, 2005, p. 184)

Parece bem evidenciado, nessa narrativa, o fato de que muito pouco conhecemos da formação escolar dessa educadora; em especial, da sua educação primária, que é uma das dimensões formadoras de sua história de vida. Esta abordagem, de cunho histórico, apresenta, como fonte documental, duas entrevistas realizadas com a prof.a Margarida de Jesus Cortez, em 6 de agosto 2015 e em 2 de junho de 2017. Também se ancora na legislação educacional vigente à época de sua educação primária.

Como objetivo precípuo, propõe-se refletir sobre os elementos educacionais e pedagógicos que influíram na formação escolar, em nivel primário, da prof.a Margarida de Jesus Cortez, em suas interações intergrupais es- 
colares prevalecentes, o que nos parece bem elucidativo de sua própria história de vida e de seus pertencimentos sociais e culturais. E com essa pretensão de construir uma narrativa acerca da formação escolar, em nível primário, da referida professora, fundamentamonos no entendimento de Delory-Momberger (2008), para quem uma história de vida e de vida escolar acontece na narrativa. Isso levando em consideração o fato de que a narrativa é o procedimento que se elabora pela reflexão e pela interpretação de uma história de vida, e de vida escolar.

Nas palavras de Delory-Momberger (2008, p. 58), melhor se explicita: “Cada experiência encontra seu lugar e adquire seu sentido no seio da forma construída pela qual o homem representa, para si mesmo, o curso de sua vida". Para essa pesquisadora é, pois, a narrativa que permite construir uma história de vida; aliás, temos uma história porque fazemos a narrativa de nossa vida.

\section{A primeira educação de escola pública}

No dia dois de agosto de mil novecentos e trinta e um nasceu, na capital Natal (Rio Grande do Norte), a prof.a Margarida de Jesus Cortez, a caçula de quatro irmãos (Maria Gizélia Cortez, Idalme Pegado Cortez, Otacílio Pegado Cortes e José Pegado Cortez), filha de Leônidas Pegado Cortez, funcionário de um estabelecimento de "café", pertencente ao irmão Emílio (localizado no bairro da Ribeira da cidade de Natal) e de Júlia Pegado Cortez, costureira especializada em roupas femininas. E é justamente sobre essa profissão de sua mãe que a prof.a Margarida (CORTEZ, 2015, p. 7) revela: “Com essa profissão ganhava a minha mãe o suficiente para manter a casa e os filhos, pois o meu pai não tinha emprego seguro". O senhor Leônidas aprendeu, apenas, a escrever o seu nome. A senhora Júlia Cortez realizou o curso primário na cidade de Goianinha (Rio Grande do Norte), onde nasceu; portanto, tinha um domínio básico da leitura, da escrita e da aritmética.

No ano de 1937, com seis anos de idade, a prof. a Margarida foi matriculada por seus pais no Grupo Escolar “João Tibúrcio”, da cidade de Natal (atualmente Escola Estadual Professor "João Tibúrcio"), localizado na rua Presidente Bandeira, no bairro do Alecrim, para, inicialmente, estudar da 1a à $5 \underline{a}$ série da educação primária estruturada na forma escolar do Grupo Escolar (Figura 1). Seus irmãos também receberam a educação primária no Grupo Escolar “João Tibúrcio".

Figura 1: Prédio do Grupo Escolar Grupo Escolar “João Tibúrcio” [1950?].

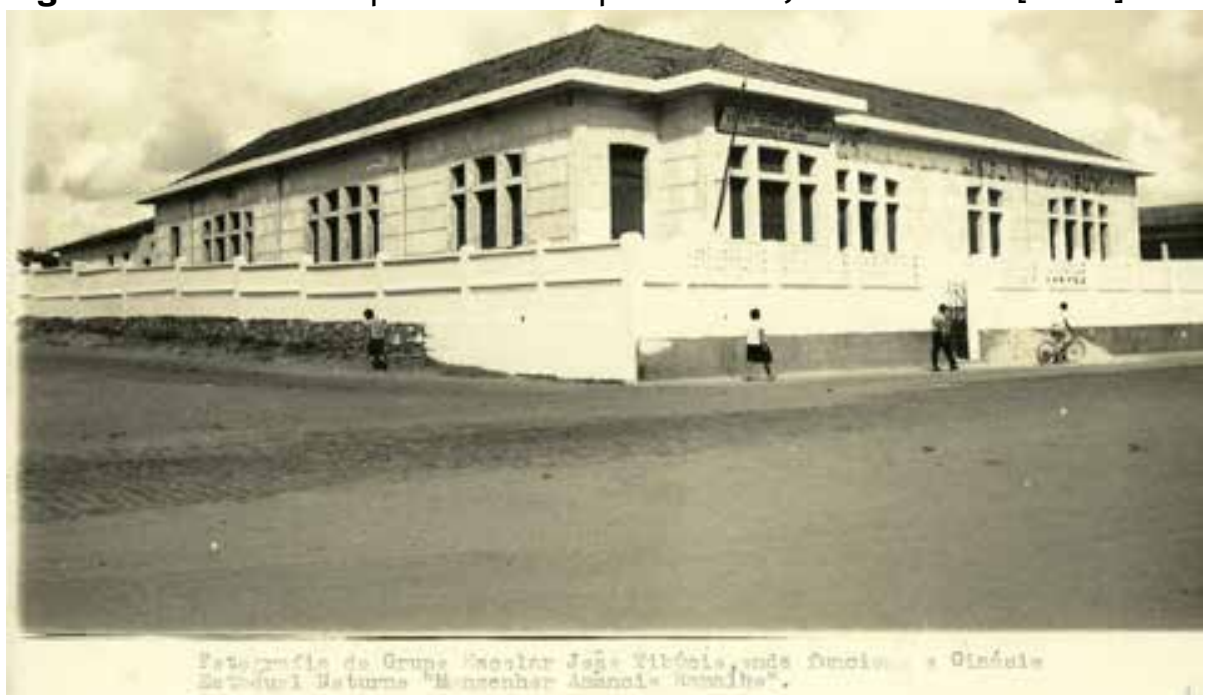

Fonte: Acervo da Escola Estadual Professor “João Tibúrcio”. 
O Grupo Escolar "João Tibúrcio" (nome dado em homenagem ao professor de Português, Francês e Latim, que lecionou por muito tempo no Atheneu Norte-Riograndense de Natal) foi criado compreendendo quatro classes primárias; uma classe de ensino complementar; uma de trabalhos manuais femininos, além de uma "escola" primária noturna (Decreto $\mathrm{n}^{\circ}$ 765, de 21 de dezembro de 1934). Sua inauguração ocorreu em 14 de abril de 1935, durante o governo de Mário Leopoldo Pereira da Câmara, quinto Interventor Federal no Estado do Rio Grande do Norte (1993-1935).

Na Interventoria de Mário Câmara, o Diretor do Departamento de Educação, professor Amphilóquio Carlos Soares Câmara, traçou um plano de Educação e Ensino (1934) voltado para ampliar as escolas primárias da modalidade grupo escolar, escolas reunidas e escolas isoladas em face da Campanha Pró-Edificações Escolares conjugada com a Campanha de Combate ao Analfabetismo, em regime de cooperação do Estado com as prefeituras municipais, visto que todos os municípios clamavam por mais e melhores escolas primárias.

$\mathrm{Na}$ amplitude da Campanha Pró-Edificações Escolares, em observância à equalização das oportunidades públicas, no tocante à educação escolar primária para as crianças, jovens e adultos, de distintas classes sociais, o Interventor Mário Câmara determinou a construção de mais de cinquenta prédios escolares nas modalidades grupo escolar, escolas reunidas e escola isolada, incluindo-se, entre eles, a construção do prédio do Grupo Escolar "João Tibúrcio". No intuito de demarcar o seu comprometimento com a equalização das oportunidades públicas da educação primária para todos, o Interventor Mário Câmara, em exposição apresentada ao Presidente da República, Getúlio Dornelles Vargas, ressalta:

A capital, com superpopulação infantil, não escapava à deficiência de escolas, visto como os dois grupos escolares e seis escolas isoladas, mantidas pelo Governo do Estado, mas funcionando as últimas em casas alugadas e imprestáveis, não poderiam atender à solicitação de todos os que procuravam matrícula. Foram construídos aqui dois novos Grupos: o 'Isabel Gondim', nas Rocas, e o 'João Tibúrcio', no Alecrim, precisamente os pontos mais densos de população e de fácil convergência. (RIO GRANDE DO NORTE, 1935, p. 72)

Sucede que a residência dos pais da prof.a Margarida se situava justamente na Rua Presidente Bandeira (bairro do Alecrim), em frente ao Grupo Escolar “João Tibúrcio - um dos pontos de maior densidade populacional da capital Natal.

Como recorda a prof.a Margarida (CORTEZ, 2015, p. 1), a sua transição entre a vida familiar e a vida escolar havia se dado em 1936: “Entrei na escola com 6 anos de idade. Já fui para a escola alfabetizada. Minha mãe me colocou à noite em uma escola particular onde havia curso de alfabetização onde aprendi a ler e a escrever". Refletir os elementos educacionais e pedagógicos que influíram na formação escolar, em nível primário, da prof.a Margarida, em suas interações intergrupais escolares prevalecentes, a priori, é elucidar uma das dimensões formativas de sua história de vida.

No Rio Grande do Norte, a educação que se instituía para a infância, na primeira etapa da vida, estava em consonância com a Lei Orgânica do Ensino de 1916 (Lei n 405, de 29 de novembro de 1916), que regulamentava o ensino primário, secundário e profissional no Estado. A educação escolar primária da prof.a Margarida, no Grupo Escolar "João Tibúrcio", foi desenvolvida por professoras mulheres: dona Orione (professora da 2á série e da 3a série primária) e dona Alcina (professora da $5 \underline{a}$ série primária), entre outras. Em contraponto, a instituição escolar era dirigida pelo professor José Saturnino. 
Considerando o fato de que uma das dimensões formativas de uma história de vida é, indispensavelmente, a educação primária, é, pois, nesse nivel de escolarização que se encontram, necessariamente, os elementos educacionais e pedagógicos da formação escolar da prof.a Margarida, como, por exemplo, o programa de estudos e os materiais pedagógicos e didáticos. Em especial, o programa de estudo foi, em parte, dirigido à sua formação e de seus colegas de classe, visando ao aprendizado da Leitura, da Escrita Caligráfica, do Português e da Gramática, da Matemática, do Desenho, das Ciências, da História do Brasil e dos Conhecimentos Gerais. No âmbito desse programa de estudo, a matéria Português foi sempre a preferida pela prof.a Margarida. De qualquer maneira, era uma aluna estudiosa e aplicada, como atestam as notas alcançadas nos exames mensais (geralmente dez), o que a desobrigava de estudar para os exames finais.

Como se vê, tudo bem de acordo com as orientações da Lei Orgânica do Ensino de 1916 (Lei $n^{\circ}$ 405, de 29 de novembro de 1916, p. 45), que assim prescrevia: "O fundamento do ensino primário consiste em leitura, escrita, cálculo e desenho, que serão cuidadosamente seriados, constituindo as demais matérias os elementos acessórios da instrução primária". A narrativa da prof.a Margarida reforça aqueles fundamentos de estudos de sua educação primária.

Para um aprendizado individual e grupal das crianças, as professoras utilizavam os seguintes materiais pedagógicos e didáticos: campainha, quadro negro, mapa, globo, espécie de mural e livros escolares (a prof.a Margarida lembra apenas o título do livro "Exame de Admissão", adotado na 5a série). Entre os materiais escolares das alunas e dos alunos, incluiam-se: cadernos com linhas em branco para os deveres de classe e de casa, caderno de caligrafia vertical, caderno de desenho com folhas em branco, lápis, caneta, tinteiro, compasso, triângulo e régua.

Com relação ao caderno contendo linhas em branco, preenchidas com os deveres diários para casa, a prof.a Margarida fez o seguinte relato: "A professora levava os nossos cadernos para casa, trazia corrigidos e comentava os erros publicamente, mas não dizendo o nome do aluno na sala de aula".

O caderno, que se situa na interface da história da infância, da história da cultura escrita e letrada e da história da educação, em última análise, é vista por Antonio Viñao (2008, p. 22) como um dos produtos da cultura escolar, “[...] uma forma determinada de organizar o trabatho de sala de aula, de ensinar e aprender, de introduzir os alunos no mundo dos saberes acadêmicos e dos ritmos, regras e pautas escolares". Assim teria sido concebido pelas professoras e pelos professores do Grupo Escolar "João Tibúrcio".

Os cadernos da prof.a Margarida aparecem, simultaneamente, associados com a escrita, a leitura, o desenho e aqueles objetos tecnológicos como lápis, caneta, tinteiro, compasso, triângulo e régua. Evidentemente, para Rogério Fernandes (2008), o caderno vem a ser um objeto de interação intergrupal entre o aluno e o professor.

$\mathrm{Na}$ sala de aula, as crianças-alunos sentavam-se em carteiras duplas ligadas com a mesinha de escrever. As professoras sentavam-se no birô posicionado em cima de um estrado. Sobre esse "arranjo espacial", a prof.a Margarida assim relatou em sua entrevista (2015, p. 6): "A professora ficava na posição mais elevada da sala de aula".

Nesta reflexão sobre os elementos educacionais e pedagógicos que influíram na formação, em nível primário, da prof.a Margarida, em suas interações intergrupais escolares prevalecentes, chama a atenção, de um modo destacado, as suas referências acerca do conjunto 
das formalidades educativas, particularmente quanto ao ritual quase místico de certas iniciações sociais cumpridas no ambiente escolar, notadamente na sala de aula. A prof.a Margarida Cortez registra bem detalhadamente essas iniciações sociais:

Em pé, do lado de fora, em frente da Escola cantava-se o Hino Nacional. Cantava-se todos os dias.

\section{[...]}

Na sala de aula tinha um ritual em que a professora fazia: batia uma palma, [os alunos] viravam-se, batia outra palma, [os alunos] sentavam, batia outra palma, [os alunos] ficavam acomodados nas carteiras.

\section{[...]}

Iniciada a aula, primeiro a professora via os exercícios de casa, colocava nota nos exercícios de casa, depois já passava a dar aula de português, de ciências, de matemática.

\section{[...]}

Tinha cópia, ditado e os exercícios que se levava para casa. Na minha opinião, o estudo nessa época era muito mais efetivo do que o atualmente. (CORTEZ, 2015, p. 4)

Todavia, a dimensão da formação escolar incluía também certas iniciações sociais formadoras, por excelência, de um sentimento de grandeza do "cosmo social", em suas interdependências com a cultura, a natureza, a civilidade urbana e os costumes unificados da vida social. A criança-aluno é, por seu turno, o futuro adulto. A dimensão da formação escolar é um dos componentes do Estado democrático, como realça Chizzotti:

O Estado, no exercício de sua jurisdição, precisa, para sua sobrevivência e seu desenvolvimento, que todos os cidadãos aprendam em um sistema estruturado de ensino, ao menos os conhecimentos básicos para participar da vida social e cultural do país e, depois, possam alcançar outros niveis de aprendizado, durante toda a vida, por meio de múltiplos processos de ensino. Todo Estado moderno organiza o respectivo sistema de educação para atender ao direito à educação para todos e garantir sua sobrevivência social e política. (CHIZZOTTI, 2016, p. 562)

Considerando essa perspectiva, a prof.a Margarida rememorou algumas das atividades festivas e cívicas organizadas e promovidas pelas professoras e professores do Grupo Escolar "João Tibúrcio" como funcionários do Estado do Rio Grande do Norte: "Festa da Árvore, Dia do Soldado e Dia da Independência, com desfile no dia 7 de setembro que vinha um soldado do Exército fazer os ensaios". No dia comemorativo do Santo Padroeiro do bairro do Alecrim - São Pedro -, os alunos eram dispensados de ir para a Escola.

A princípio, pela Lei $n^{\circ} 405$, de 29 de novembro de 1916, a educação primária era pública e laica, e os professores não poderiam ensinar, na escola, qualquer doutrina religiosa, o que foi ratificado pela prof.a Margarida. Ainda por essa Lei de 1916, para os cuidados com a higiene pessoal das alunas e dos alunos, os professores, antes do início dos trabalhos escolares, deviam verificar se eles estavam devidamente asseados no corpo e na roupa. o relato, a seguir, foi também corroborado pela prof.a Margarida: “Todos os dias tinha que mostrar as unhas, via se estavam limpas, tinha uma revista diária. As condições de higiene sempre eram observadas. Era uma prática de civilidade da escola".

A socialização escolar dessas crianças-alunas expandia-se, necessariamente, para a obediência às regras e às normas que orientavam a vida na sala de aula e no dia a dia, a exemplo dos costumes de higiene pessoal e, igualmente, de hábitos de conduta social, de disciplina e de controle de si mesmo. E para além, ainda preconizava a Lei do Ensino de 1916:

As lições de moral serão dadas em lugar próprio, no horário de todas as classes, aprovei- 
tando-se, quanto possivel, os estímulos que derivam da vida escolar, social e familiar, a oportunidade das boas ou más ações dos alunos, para os estimular ou corrigir por meio do conselho e, sobretudo, do exemplo. (RIO GRANDE DO NORTE, 1917, p. 46)

A prof. a Margarida enfatizou que, no Grupo Escolar "João Tibúrcio", os alunos não eram castigados pelas professoras e pelos professores. Para conferir veracidade ao que era regulamentado e ao que era praticado pelos professores, assim testemunha a prof.a Margarida: “Às vezes [alguns alunos] iam para a diretoria da Escola, mas era raro, não era prática comum". E o que dizer das expectativas dos pais? Ora, a família e a sociedade esperavam que a educação escolar preparasse devidamente as novas gerações para a vida civil. Ademais, acreditavam que os conhecimentos ensinados às novas gerações fossem suficientes para torná-las bem-sucedidas em suas escolhas profissionais e sociais. Para a prof. a Margarida, a escola devia ensinar a criança a gostar de estudar:

Eu adorava ir para a escola. Achava maravilhoso ler para ir para a escola. A educação primária foi que me deu o impulso para estudar. Eu sempre gostei de estudar, eu amava os livros. (CORTEZ, 2015, p. 7)

A formação escolar, em nível da educação primária, da prof.a Margarida, no Grupo Escolar "João Tibúrcio", compreendia os princípios de equidade, de laicidade, de direito à educação primária, de reconhecimento público e de continuidade dos estudos escolares.

Referenciada por esses princípios civis e sociais, a sua formação escolar abrangeu outro rito social: o hábito de chegar todos os dias bem cedo. Qual seria o porquê do cultivo desse hábito? A prof.a Margarida alegou que a pontualidade, na antecipação do horário de chegada ao Grupo Escolar "João Tibúrcio", era essencial para estudar suas lições de piano no próprio piano da escola. E foi justamente por instituir a si mesma essa disciplina que conseguiu ir aprimorando o gosto pela música ou pela sonoridade musical desse instrumento clássico. O testemunho da prof.a Margarida é esclarecedor:

$\mathrm{Na}$ Escola havia um piano, eu gostava muito de estudar piano e eu estudava piano no [Conservatório de Música], então eu ia bem cedinho antes de chegarem os alunos e fazia a minha lição de piano, todos os dias. (CORTEZ, 2015, p. 4)

Como revela, em seu relato, era aluna do Conservatório de Música, que funcionava nas dependências do Teatro Alberto Maranhão. 0 seu entusiasmo pelas estreias, pelo reconhecimento artístico, bem como sua curiosidade infantil, provavelmente a instigaram ao cultivo de outros hábitos e de outros aprendizados. Onde há admissibilidade crescente do cultivo de outros hábitos há, igualmente, para Dewey (1971, p. 26), “[...] a formação de atitudes tanto emocionais, quanto intelectuais; envolve toda nossa sensibilidade e modos de receber e responder a todas as condições que defrontamos na vida".

Na vida escolar, em nível primário, da prof.a Margarida, pela transmissão intergeracional, teria havido um tempo psicológico para estudar e aprender rituais de entrada na sala de aula e de saída desta, pré-requisitos e deveres sociais, a exemplo da obrigatoriedade da farda escolar. No Grupo Escolar "João Tibúrcio", conforme ela, as meninas vestiam uma farda escolar composta de uma blusa de cor branca com gravatinha azul e uma saia pregueada de cor azul. E os meninos vestiam camisa e calça de cor cáqui.

Todos esses elementos educacionais e pedagógicos, conforme Dussel (2014, p. 262), têm suas funções não só “[...] em termos de socialização e experiência de vida, mas também em termos de conhecimentos que produzem, [...] dos agrupamentos das pessoas, e das hierar- 
quias que constroem". Em contrapartida, deve ter havido, concomitantemente, amizades, brincadeiras, competições. Todos esses elementos educacionais e pedagógicos é que se podem mostrar mais reveladores de sua satisfação cultural de prosseguir em direção aos outros níveis escolares para, assim:

[...] adquirir uma visão junto dos problemas e das tarefas; fazer aparecer os elos entre o que vejo, o que penso viver - e os acontecimentos que atravessam o mundo. E assim, apreendo mais dados e os apreendo com mais acuidade, pois eles iluminam-se uns pelos outros. E ao mesmo tempo, sou concernido por mais, participo mais, é assim que posso esperar compreender meu lugar, encontrar e tomar o meu lugar. (SNYDERS, 1988, p. 51)

Não se pode, pois, senão, constatar esta verdade: onde há acolhimento crescente do cultivo de outros aprendizados, há, outrossim, como bem elucida Snyders (1988), uma alegria em direção à confiança em si mesmo; uma alegria da força de agir com liberdade de salutares escolhas, além de uma alegria de se abrir para o mundo. Sob a ótica da prof.a Margarida, sua educação primária "[...] abriu as portas para os outros níveis de estudo".

Em seu livro, Petitat (1994, p. 19) define a educação escolar como socializadora, ao mesmo tempo em que define a escola como "[...] uma instituição intermediária que age duplamente, de um lado, junto aos indivíduos e suas famílias, e, de outro, junto à comunidade societal e sua hierarquia".

\section{Conclusão}

O tempo principiante da criança-aluno, por sua vez, é um tempo de alteridades, conforme mostra Delory-Momberger (2008), no curso da formação acadêmica, física, moral, social, psíquica, sentimental. Esse tempo é, deveras, como ainda observou Snyders (1988, p. 207208), o tempo psicológico de aprender a gostar de estudar, de desejar continuar com essa satisfação cultural “[...] e de também sentir-se capaz de olhar além do presente; do imediato, agir a longo prazo, engajar-se por um longo prazo; todas as alegrias que, ao mesmo tempo supõem e fortalecem a confiança no futuro".

Esse tempo da formação escolar, em nivel primário, da prof.a Margarida, em suas interações intergrupais, evidentemente, com suas ansiedades, angústias e desejos de vencer cada etapa de sua vida é, pois, elucidativo da narração de sua própria história de vida, de largueza existencial nas situações educativas, de esposa (casou em 1966 com Geraldo Magela da Silva e descasou em 1976), e de mãe de quatro filhas: Jean Daisy Cortez Nobre (formada em História pela Universidade de Brasília), Valéria Suely Cortez da Silva (formada em Odontologia pela Universidade Federal do Rio Grande do Norte), Denise Cortez da Silva Accioly (formada em Comunicação Social, além de mestra e doutora em Educação, pela Universidade Federal do Rio Grande do Norte) e Ana Margareth Cortez da Silva Rosa (formada em Odontologia, também pela Universidade Federal do Rio Grande do Norte).

A prof.a Margarida, por meio do exame de Admissão, ingressou no Atheneu Norte-RioGrandense, juntamente com duas colegas de educação primária (Severina e Rita Eufrásio) - diga-se no Atheneu Feminino, para cursar o nível secundário ginasial e clássico (1946-1951), cujo currículo formador era tipo "enciclopédico": Português, Francês, Inglês, Latim, Matemática, Desenho, Música, História Geral e do Brasil, História da Civilização, Geografia Geral e do Brasil, Educação Física, afora outras matérias. Logo depois, cursou o Normal na Escola Normal de Natal (1951-1953) hoje, o Instituto Su- 
perior de Formação de Professores Presidente Kennedy.

Tendo concluído essa última etapa, logo foi incentivada pela prof.a Clea Bezerra de Mello a ingressar na Faculdade de Filosofia Ciências e Letras de Recife, para cursar Pedagogia (19521956). O relato da prof.a Margarida (2015, p. 7) é esclarecedor de alguns detalhes a mais: “O tio dela [prof.a Clea] que era o prof. Severino Bezerra, Secretário de Educação do Estado, ao me nomear como professora, fez-me a seguinte pergunta: "Você quer ir ensinar ou você quer ir continuar seus estudos?" Eu disse: "Quero continuar os meus estudos". Ele, então, deu seu consentimento desde que eu que ficasse à disposição do Instituto Pestalozzi, de Recife. Na Faculdade de Filosofia Ciências e Letras, foi selecionada para uma Bolsa de Estudos concedida pelo Diretório Acadêmico dos Estudantes. Regressando a Natal, foi nomeada professora de Matemática do Atheneu Norte-Rio-Grandense, colégio onde havia feito o curso secundário.

No último ano da década de cinquenta do século XX, fez o Curso de Especialista em Educação para a América Latina (1959), promovido pela Organização das Nações Unidas para a Educação, Ciência e Cultura (Unesco), em colaboração com o Ministério da Educação e Cultura e o Ministério do Exterior, realizado na Universidade de São Paulo. No ano seguinte, conforme relatou, a convite do então Diretor, ingressa na Faculdade de Filosofia Ciências e Letras (quando de sua federalização para ensinar Didática Geral), em que permanece até sua aposentadoria (1990).

Tentar outras iniciações que associassem projetos diretamente vinculados à emancipação de crianças, de jovens e de adultos da classe trabalhadora, fez com que a prof.a Margarida se integrasse, em outubro de 1961, à Campanha de Pé no Chão Também se Aprende a Ler, permanecendo até março de 1964 à disposição da Secretaria de Educação de Natal, quando foi afastada. Na manhã de 20 de maio de 1964 , foi presa no Quartel do $16^{\circ} \mathrm{Re}$ gimento de Infantaria, onde ficou detida por vinte e dois dias. Foi acusada de subversiva, por envolvimento em situações que atentavam contra a democracia. Seus projetos político-educacionais, no entanto, só almejavam a emancipação da classe trabalhadora. Residiria aí seu engajamento político? E sua "conduta subversiva"? Dessa acusação, ela se defende:

Eu estava absolutamente comprometida com a democratização do saber, com a difusão da cultura letrada e a formação de professores capazes de assumirem compromisso com a educação daquelas crianças, cuja oportunidade de serem alfabetizadas thes havia sido negada. (CORTEZ, 2005, p. 20-21)

\section{[...]}

Ao recordar todo aquele passado, tive momentos de alegria, mas também experimentei instantes de profunda tristeza. Alegria, por saber que fiz o melhor dentro daquele contexto histórico, e tristeza, por relembrar que tudo havia acabado. Porém, ao recordar minhas memórias, em momento algum me senti fracassada. A mesma esperança que sempre alimentou meus ideais continua viva. (CORTEZ, 2005, p. 214)

Antes de tudo, a prof.a Margarida de Jesus Cortez (2005, p. 20), intelectual, engajada na satisfação de colocar em prática suas ideias político-pedagógicas à serventia da educação da classe trabalhadora, foi a formuladora do Centro de Formação de Professores da Secretaria Municipal de Educação de Natal e Coordenadora Técnico-Pedagógica da Campanha de Pé no Chão Também se Aprende a Ler, durante o governo do prefeito Djalma Maranhão. Totalmente entusiasmada, a prof.a Margarida Cortez (2005, p. 5) admite: “[...] pretendia alfabetizar as crianças e os adultos que não tinham tido o direito de serem alfabetizados em tempo oportuno, de conhecerem o mundo das 
letras, e se prepararem para o exercício pleno da cidadania".

Em razão de seu afastamento da docência na Faculdade de Filosofia, Ciências e Letras de Natal; da demissão do cargo de professora do Atheneu Norte-Rio-Grandense e da exoneração ex-ofício do cargo de professora interina do Ginásio Normal do município de Macaíba (Rio Grande do Norte), não obstante a confiança em si mesma para viver ou mesmo para sobreviver, bem como a confiança na sua formação acadêmica, desde a educação primária à educação universitária, a prof.a Margarida Cortez ousou outra iniciação existencial: ser aluna de um Curso de Administração Escolar na Universidade de São Paulo (1969). Essa iniciação foi possivel graças ao então Secretário de Estado da Educação e Cultura, professor Grimaldi Ribeiro, que the concedeu uma bolsa de estudos.

No ano de 1979, a prof.a Margarida Cortez foi anistiada, reassumindo, portanto, suas funções de docente na Universidade Federal do Rio Grande do Norte e na Secretaria de Estado da Educação e Cultura. No ano de 1983, foi aprovada no Mestrado de Educação, da Pontifícia Universidade Católica de São Paulo, mas, por problemas familiares, não defendeu a dissertação de mestrado.

Passados mais de sessenta anos de seu ingresso na educação primária do Grupo Escolar "João Tibúrcio", e passados mais de dez anos de sua aposentadoria, a prof.a Margarida foi aprovada no curso de doutorado do Programa de Pós-Graduação em Educação, da Universidade Federal do Rio Grande do Norte. A sua duradoura satisfação pessoal e cultural guarda profunda semelhança com cada projeto acadêmico e intelectual a que se dedicou. No seu relato, é deveras enfática nessa sua revelação: "Realizei o doutorado após minha aposentadoria (1999-2003). Minha intenção não era ganhar dinheiro, tampouco ganhar status.
A [minha intenção] era atualizar meus conhecimentos". A tese de doutorado defendida intitulou-se "A prática alfabetizadora em questão: competências necessárias". Voltou à Universidade - pelo período de treze anos - com o contrato de Professora Substituta (1995-2008).

Pelas teorizações de Delory-Momberger (2008), a narrativa é o procedimento que se experimenta e se elabora pela reflexão e pela interpretação de uma história de vida, e de vida escolar. Refletir acerca da sua educação primária foi, para a prof.a Margarida (2017, p. 7), meditar o quanto esse nível de estudo foi fundamental para sua vida profissional, como atestam suas próprias palavras: “[...] porque me abriu as portas para os outros niveis de estudo". Por conseguinte, a sua formação escolar, mediante a sua educação primária no Grupo Escolar "João Tibúrcio", teria sido o começo de uma longa vida existencial e acadêmica, de alegrias culturais e de muitas iniciações existenciais na sua história de vida. É o que se confirma por suas palavras:

O começo da minha vida acadêmica. [...] O começo da minha ascensão profissional, como estudante, como pessoa mais esclarecida, como pessoa que se abre para a vida. A escolarização primária foi que me deu o impulso para estudar. Eu sempre gostei de estudar, eu amava os livros. (CORTEZ, 2015, p. 6)

Reconstituir os elementos educacionais e pedagógicos que influíram na formação escolar, em nível primário, da prof.a Margarida Cortez, em suas interações intergrupais escolares prevalecentes, concorreu para elucidar uma das dimensões formativas de sua história de vida - a educação primária. Todavia, podem se mostrar mais reveladores daquilo que Mignot e Cunha almejam:

[...] a esperança de que o entendimento da importância dessas escritas, para a memória da educação brasileira, desperte, em cada um e em todos que o lerem, um compromisso com 
a preservação, compromisso esse que emerge da função social da memória. (MIGNOT; CUNHA, 2006, p. 43)

Nesta narração, reside a perseverança da memória do domínio da formação escolar em nível primário para a vida adulta; reside, sem dúvida, a satisfação cultural da prof.a Margarida Cortez, o fascínio do registro de sua própria vida escolar, acadêmica, bem como de uma intelectual engajada na emancipação de crianças, jovens e adultos da classe trabalhadora por meio da educação escolar para todos. É, bem mais, o relato da alegria cultural de seus ideais de vida, sempre vivedouros e renovadores.

\section{Referências}

CAMPANHA De Pé no Chão Também se Aprende a Ler. Entrevista com Moacyr de Góes. Revista Educação em Questão, Natal, v. 36, n. 22, p. 227-239, set./ dez. 2009.

CHIZZOTTI, Antonio. Políticas públicas: direito de aprender e avaliação formativa. Práxis Educativas, Ponta Grossa, v. 11, n. 3, p. 561-576, set./dez. 2016.

CORTEZ, Margarida de Jesus. Memórias da Campanha "De Pé no Chão Também Se Aprende a Ler". Reflexões sobre a prática pedagógica de ontem e de hoje. Natal: Editora da UFRN, 2005.

. A educação escolar primária da prof.a Margarida de Jesus Cortez. Natal, 6 ago. 2015. (Entrevista feita pela prof.a Marta Maria de Araújo; gravada e filmada pela prof.a Berenice Pinto Marques).

- A educação secundária da prof.a Margarida de Jesus Cortez. Natal, 2 jun. 2017. (Entrevistas gravadas e realizadas por Berenice Pinto Marques e Ana Luiza Medeiros).

DELORY-MOMBERGER, Christine. Biografia e educação. Figuras do indivíduo projeto. Tradução Maria da Conceição Passeggi, João Gomes da Silva Neto e Luis Passeggi. Natal: Editora da UFRN; São Paulo: Paulus, 2008.

DEWEY, John. Experiência e educação. Tradução de
Anísio Teixeira. São Paulo: Companhia Editora Nacional, 1971.

DUSSEL, Inés. A montagem da escolarização: discutindo conceitos e modelos para entender a produção histórica da escola moderna. Revista Linhas, Florianópolis, v. 15, n. 28, p. 250-278, jan./jun. 2014.

EDUCAÇÃO e Ensino. A República, Natal, p. 2, 16 fev. 1934.

FERNANDES, Rogério. Um marco no território da criança: o caderno escolar. In: MIGNOT, Ana Chrystina Venancio. (Org.). Cadernos à vista. Escola, memória e cultura escrita. Rio de Janeiro: EdUERJ, 2008. p. 49-68.

GOÉS, Moacyr de. De Pé no Chão Também se Aprende a Ler (1961-1964). Uma escola democrática. Rio de Janeiro: Civilização Brasileira, 1980.

Prefácio. In: Memórias da Campanha “De Pé no Chão Também Se Aprende a Ler." Reflexões sobre a prática pedagógica de ontem e de hoje. Natal: EDUFRN - Editora da UFRN, 2005. p. 15-18.

MIGNOT, Ana Chrystina Venancio; CUNHA, Maria Teresa Santos. Razões para guardar: a escrita ordinária em arquivos de professores/as. Revista Educação em Questão, Natal, v. 25, n. 11, p. 40-61, jan./abr. 2006.

PETITAT, André. Produção da escola/produção da sociedade: análise sócio-histórica de alguns momentos decisivos da evolução escolar no ocidente. Tradução de Eunice Gruman. Porto Alegre: Artes Médicas, 1994.

RIO GRANDE DO NORTE. Lei $\mathbf{n}^{\circ}$ 405, de 29 de novembro de 1916. Lei Orgânica do Ensino. Reorganiza o ensino primário, secundário e profissional, no Estado. Natal: Typographia d'A República, 1917.

Decreto n 765, de 21 de dezembro de 1934. Cria no bairro do Alecrim, nesta capital, um grupo escolar denominado "João Tibúrcio". Decretos do governo de julho a dezembro (1934). Natal: Imprensa Oficial, 1934.

Exposição apresentada ao Exmo. Sr. Dr. Getúlio Vargas - M. D. Presidente da República, pelo 
Interventor Federal no Rio Grande do Norte Mario Leopoldo Pereira da Câmara. Natal: Imprensa Oficial, 1935.

SNYDERS, Georges. A alegria na escola. Tradução de Bertha Halpera Guzovitz e Maria Cristina Caponero. São Paulo: Editora Manole Ltda, 1988.

VIÑAO, Antonio. Cadernos escolares como fonte his- tórica: aspectos metodológicos e historiográficos. In: MIGNOT, Ana Chrystina Venancio. (Org.). Cadernos à vista. Escola, memória e cultura escrita. Rio de Janeiro: EdUERJ, 2008. p. 15-33.

Recebido em: 18.07.2017

Aprovado em: 19.08 .2018

Marta Maria de Araújo é Prof.a Titular da Universidade Federal do Rio Grande do Norte. Líder do Grupo de Pesquisa Estudos Históricos Educacionais (UFRN/CNPq). Coordenadora do Grupo de Pesquisa Interinstitucional Mulheres e Educação. Integrante do Grupo Interdisciplinar de Pesquisa, Formação (Auto)Biografia e Representações (GRIFAR/UFRN/ CNPq).e-mail:martaujo@uol.com.br.

Av. Hermes da Fonseca, 1444. Apto 402. Bairro Tirol. Telefone (84) 999-255629.

Berenice Pinto Marques é doutoranda do Programa de Pós-Graduação em Educação da Universidade Federal do Rio Grande do Norte. Integra o Grupo de Pesquisa Estudos Históricos Educacionais (UFRN/CNPq).

e-mail: berenicemarques3@hotmail.com.

Rua Vereador Orlando Garcia, 1420. Apto 505. Bairro Lagoa Nova. Telefone: (84) 99670-1022.

Ana Luiza Medeiros é doutoranda do Programa de Pós-Graduação em Educação da Universidade Federal do Rio Grande do Norte. Integra o Grupo de Pesquisa Estudos Históricos Educacionais (UFRN/CNPq). e-mail: aurorauta@gmail.com.

Rua do Ouro, 145. Bairro Lagoa Nova. Telefone (84) 999635628. 